\section{Analyzing the adoption of radiofrequency ablation of thyroid nodules using the diffusion of innovations theory: understanding where we are in the United States?}

Jennifer H. Kuo, Catherine McManus, James A. Lee

Section of Endocrine Surgery, Columbia University, New York, NY, USA

Thyroid nodules are very common and found in up to $68 \%$ of the general U.S. population on ultrasound. Although thyroidectomy has long been the mainstay of treatment for malignant and symptomatic benign thyroid nodules, various interventional ablative techniques have emerged in the last couple of decades as alternative non-surgical treatment options. Globally, the most widely adopted technique has been ultrasound-guided radiofrequency ablation (RFA). RFA of thyroid nodules was first performed in 2002, and there has been an expanding body of evidence since 2006 showing that RFA and other interventional ablative techniques are effective treatments for benign solid thyroid nodules, toxic adenomas, and thyroid cysts. More recently, evidence has emerged that these techniques may be effective treatment for low-risk thyroid cancer and recurrent disease. Despite these findings, the United States has been slow to adopt these techniques, with only a single publication on RFA more than a decade after the first series was published. EM Rogers' Diffusion of Innovation Theory provides us the appropriate lens to carefully analyze the process of adoption of RFA for thyroid nodules-to understand where we are currently, as well as, the important next steps that must be accomplished in order for RFA and other ablative techniques to be successfully adopted into the management algorithm of thyroid nodules in the United States.

Keywords: Thyroid radiofrequency ablation; Innovation; Adoption curve; Diffusion Key points: Radiofrequency ablation (RFA) for thyroid nodules is a classic example of a medical innovation that takes an existing technology and applies it to a new indication. RFA has all the attributes to be successfully adopted and diffuse into society. US Physicians are "early adopters" and will make a significant contribution to help surpass "tipping point" for RFA of thyroid nodules and ensure successful widespread diffusion of innovation.

\section{Introduction}

Radiofrequency ablation (RFA) of thyroid nodules is the application of radiofrequency waves to

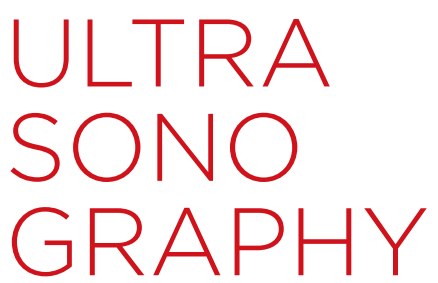

REVIEW ARTICLE

https://doi.org/10.14366/usg.21117 pISSN: 2288-5919 e elSSN: 2288-5943 Ultrasonography 2022;41:25-33

Received: June 2, 2021

Revised: June 26, 2021

Accepted: July 1, 2021

Correspondence to: Jennifer H. Kuo, MD, MS, Section of Endocrine Surgery, Columbia University, 161 Fort Washington Ave, Suite 829, New York, NY 10032, USA

Tel. +1-212-305-6969

Fax. +1-212-305-0445

E-mail: jhk2029@cumc.columbia.edu

This is an Open Access article distributed under the terms of the Creative Commons Attribution NonCommercial License (http://creativecommons.org/ licenses/by-nc/4.0/) which permits unrestricted noncommercial use, distribution, and reproduction in any medium, provided the original work is properly cited.

Copyright (C) 2022 Korean Society of Ultrasound in Medicine (KSUM)

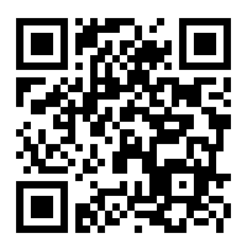

How to cite this article:

Kuo JH, McManus C, Lee JA. Analyzing the adoption of radiofrequency ablation of thyroid nodules using the diffusion of innovations theory: understanding where we are in the United States? Ultrasonography. 2022 Jan;41(1):25-33. 
cause thermal injury and subsequent necrosis of the tissue. Gradual reabsorption of the ablated tissue results in overall volume reduction of the thyroid nodules. Similar to other innovations in healthcare, RFA of thyroid nodules is a new application of an existing technology to address an unmet clinical need, i.e., nonsurgical management of thyroid nodules. Thyroid nodules are a prevalent clinical problem with up to $68 \%$ of the population having one or more lesions detected with high-resolution ultrasound [1]. Although most benign nodules can be safely observed, a portion of these nodules require definitive management due to significant size, continued growth, compressive symptoms, cosmesis, and/ or autonomous function leading to hyperthyroidism $[1,2]$. Surgical resection has long been the mainstay of treatment for these benign, but problematic nodules. In fact, of the approximately 140,000 thyroid operations performed each year in the United States, twothirds are performed for benign disease [3]. Although associated with excellent outcomes in experienced hands, thyroidectomy still carries a low risk of complications that include recurrent or superior laryngeal nerve injury leading to voice changes, hypoparathyroidism, bleeding, infection, hypothyroidism with need for thyroid hormone supplementation, and scarring [3].

At the end of the 20th century, advances in medical technology facilitated the shift towards minimally invasive operations and interventions. Management of thyroid disease is no exception. Thyroidectomy incisions have significantly decreased in size since Kocher first popularized his low collar incision in the late 19th century [4]. In the past decade, advancements in endoscopic and robotic surgery have enabled remote access approaches that avoid visible cervical incisions [5]. However, these approaches still leave scars that are more or less visible and carry the not insignificant potential need for thyroid hormone replacement. In the past couple of years, there has been great enthusiasm for RFA in the United States and its potential role in the management of benign and potentially malignant thyroid nodules [6]. Many believe that this "new" innovation will revolutionize the management of thyroid nodules by obviating the need for an operation completely. The first RFA of thyroid nodules was performed in 2002 and the first case series was published in 2006 in Seoul, South Korea [7]. Since that time RFA, as well as other thermal ablation techniques, have been widely adopted across Asia and Europe [8-11], and has been newly introduced in the United States in the last few years. Although there is an increased awareness of RFA for thyroid nodules, this technique is still only offered by a handful of institutions across the country.

Why has it taken so long for the United States to adopt RFA of thyroid nodules? Will this innovation truly "revolutionize" the management of thyroid nodules and be widely integrated into clinical treatment algorithms? The fact that the Food and Drug
Administration did not approve the use of RFA for soft tissue masses until February 2018 certainly contributed to the delay in the adoption process, but that is unlikely the whole explanation. In 1962, Everett Rogers, a communication theorist and sociologist, published Diffusion of Innovations detailing one of the most popular frameworks for understanding the complex process of the adoption and diffusion of innovations [12]. This paper aims to analyze the adoption of RFA of thyroid nodules within the framework of Rogers' Diffusion of Innovation (DOI) Theory to gain a greater understanding of the adoption process for RFA, where we currently stand in the United States, and the expected trajectory of RFA of thyroid nodules in the future.

\section{Diffusion of Innovation}

Innovation can be defined as 'invention+adoption+diffusion' [13]. Diffusion is the social process that occurs in response to learning about an innovation as it is communicated through certain channels over time among the members of a social system [12]. It can be assessed at various levels: individuals, organizations, or larger groups within society. Rogers' DOI Theory recognizes that this adoption and diffusion process of innovations generally takes place over many years. When time-of-adoption data are graphed cumulatively, an S-shaped curve is common (Fig. 1), with an initial slow rate of adoption giving way to a rapidly accelerating rate, which then slows as fewer nonadopters remain within the social system in question [12]. Not all instances of innovation play out this way, and in fact, most innovations fail to be widely adopted and diffused into society. To better understand the success, or lack of, diffusion of innovations, Rogers' theory is comprised of four main elements: innovation, communication channels, individual adopters and the adoption process, and the social system.

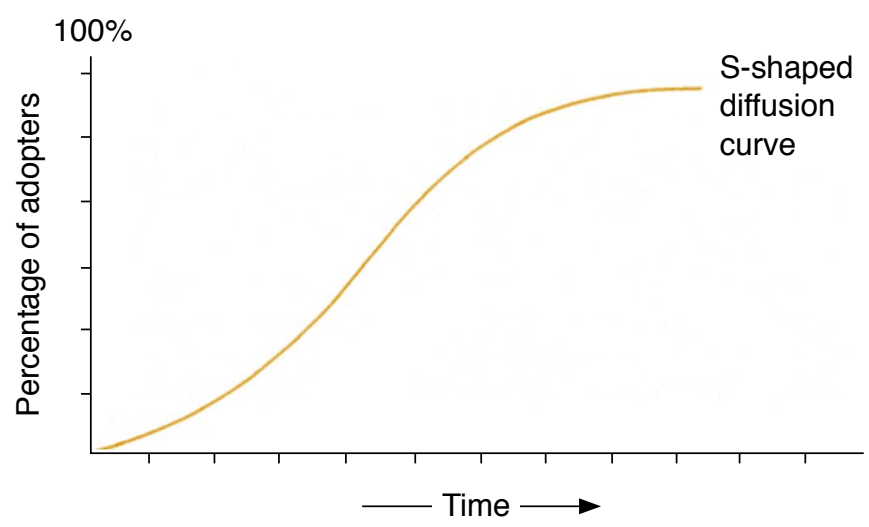

Fig. 1. The S-curve of the adoption of innovation. 


\section{Innovation}

Rogers describes the innovation-diffusion process as essentially "an uncertainty reduction process." In other words, the less uncertainty that surrounds an innovation and its adoption, the greater chance that it will be diffused into wide-spread use in society. There are five attributes or characteristics of innovations that help to decrease its uncertainty: relative advantage, compatibility, complexity, trialability, and observability.

Relative advantage is "the degree to which an innovation is perceived as being better than the idea it supersedes" [12]. RFA of thyroid nodules offer several advantages compared to thyroidectomy:

- Ability to perform the procedure in an office-based setting without the need for general anesthesia

- Reduced cost when compared to operating room-based procedures

- Less invasive profile than surgery

- Shorter recovery time

- Lack of a visible scar

- Vastly reduced risk of permanent hypothyroidism

The vanishingly low risk of permanent hypothyroidism is perhaps the greatest motivator for the adoption of RFA in the United States and truly differentiates RFA from preceding innovations in the management of thyroid nodules. Although these advantages are well documented in international series $[8,9]$, there remains a dearth of data in the United States. However, this will likely change over the next few months as several institutions in the United States publish their outcomes from their early experience.

Compatibility is "the degree to which an innovation is perceived as consistent with the existing values, past experiences, and needs of potential adopters" [12]. If an innovation is compatible with an individual's needs, the rate of adoption of the innovation will increase. One of the greatest advantages of RFA for thyroid nodules is the ability to integrate it into most existing practice settings. While interventional radiologists (and some surgeons) continue to perform these procedures in an ambulatory hospital setting, most surgeons and medical endocrinologists perform these procedures in an office-based setting. In contrast, one of the greatest obstacles for compatibility is the lack of a specific Current Procedural Terminology (CPT) Code for RFA of thyroid nodules, which often results in nonreimbursement for these procedures by insurance payors. Although there is a collaborative effort by several medical societies to apply for a CPT code, this effort will likely take several years. In the interim, these procedures often have to be performed on a fee for service basis which places a financial burden on patients and can limit the number of patients who can access the procedure.
Complexity is "the degree to which an innovation is perceived as relatively difficult to understand and use" [12]. Excessive complexity of an innovation is an important obstacle in its adoption. Fortunately, RFA of thyroid nodules is a rather simple concept that is easily grasped by the lay public and professionals alike. However, the technique itself requires an additional skill set to perform safely and effectively, since a significant amount of thermal energy is delivered in a very small space that is adjacent to critical structures. While the technique superficially bears many similarities to other thyroid interventions like fine needle aspiration biopsy, several unique techniques have been developed to optimize outcomes including hydrodissection, the trans-isthmic approach, the movingshot technique [8], artery-first-ablation, and marginal vein ablation [14]. These techniques require a clinical skill set that often needs to be developed, even by those with existing expertise in sonography and fine needle aspiration biopsy. Learning this critical skill set adds a layer of complexity for any individual seeking to adopt RFA, but one that can be overcome with the appropriate training.

The last two characteristics of a successful innovation are trialability, "the degree to which an innovation may be experimented with on a limited basis," and observability, "the degree to which the results of an innovation are visible to others" [12]. The more an innovation is tried, the faster it is typically adopted. The ability to provide opportunities to observe, teach, and trial RFA of thyroid nodules in the United States has been largely impeded by the social-distancing and travel restrictions of the coronavirus disease 2019 pandemic. In lieu of in-person courses, several webinars have occurred in the last couple of years that have been successful in generating enthusiasm for RFA. In addition, there have been several innovative trials of virtual clinical observations, hands-on courses, and proctoring that have been met with variable success. As the immediate threat of the pandemic subsides, it is expected that inperson hands-on courses and direct proctoring by experts will be in great demand.

As an innovation, RFA of thyroid nodules appears to have all of the attributes that comprise a successful innovation. However, even some of the best innovations have not successfully diffused into society based on merit alone. As Rogers delineates, the success of an innovation is also heavily influenced by how well and how quickly it is communicated to a society.

\section{Communication Channels}

The second element of the diffusion of innovations process is communication channels [12]. For Rogers, communication is "a process in which participants create and share information with one another in order to reach a mutual understanding." In medicine 


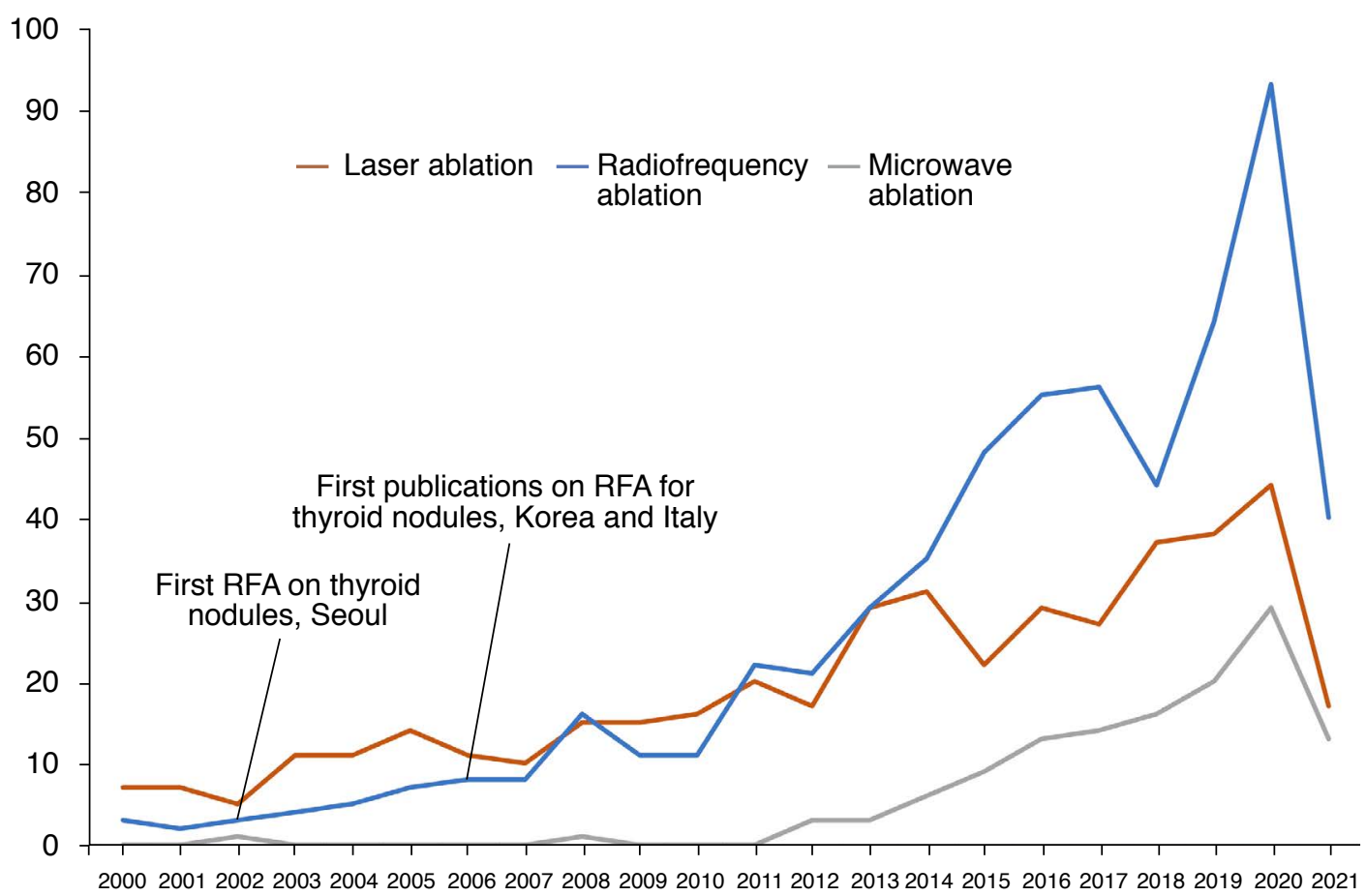

Fig. 2. Number of scientific publications on thermal ablative techniques since 2000 (Web of Science search). RFA, radiofrequency ablation.

and healthcare, the most commonly used form of communication is publications in scientific journals. Fig. 2 shows the exponential rise in the number of publications on thermal ablative techniques since 2000. Of note, RFA is the most widely used and studied thermal ablation technique for thyroid nodules.

\section{Individual Adopters and the Adoption Process}

Rogers describes the innovation-decision process as "an information-seeking and information-processing activity, where an individual is motivated to reduce uncertainty about the advantages and disadvantages of an innovation" [12]. This innovation-decision process involves five sequential stages: knowledge, persuasion, decision, implementation, and confirmation, as summarized in Fig. 3.

The innovation-decision process starts with the knowledge stage. In this step, an individual learns about the existence of the innovation (awareness-knowledge), how to use the innovation correctly (how-to-knowledge), and seeks to understand the functioning principles describing how and why the innovation works (principles-knowledge) [12]. Although an innovation can be adopted without all three types of knowledge, incomplete knowledge can lead to the misuse of the innovation and ultimately cause a backlash and ultimate discontinuance.

The "persuasion stage" occurs when the individual develops a negative or positive attitude toward the innovation, after gaining knowledge about the innovation. It is important to note that "the formation of a favorable or unfavorable attitude toward an innovation does not always lead directly or indirectly to an adoption or rejection" [12]. In contrast to the knowledge stage that is more cognitive-centered, the persuasion stage is more affectivecentered (i.e., feeling-centered). The degree of uncertainty about the innovation's functioning and the social reinforcement from others (colleagues, peers, etc.) affect the individual's opinions and beliefs about the innovation.

At the "decision stage," the individual chooses to adopt or reject the innovation. Rogers expressed two types of rejection: active rejection and passive rejection [12]. In active rejection, an individual tries the innovation and thinks about adopting it, but later decides not to adopt it. In a passive rejection (or non-adoption) position, the individual does not think about adopting the innovation at all.

At the "implementation stage," an innovation is put into practice. During implementation, it is important to reduce the degree of uncertainty about the consequences of adoption as much as possible. Reinvention, "the degree to which an innovation is changed or modified by a user in the process of its adoption and implementation" is a critical component of the implementation stage [12]. By tailoring the innovation to work effectively in the user's local environment and practice, he or she is reducing barriers 


\section{Communication channels}

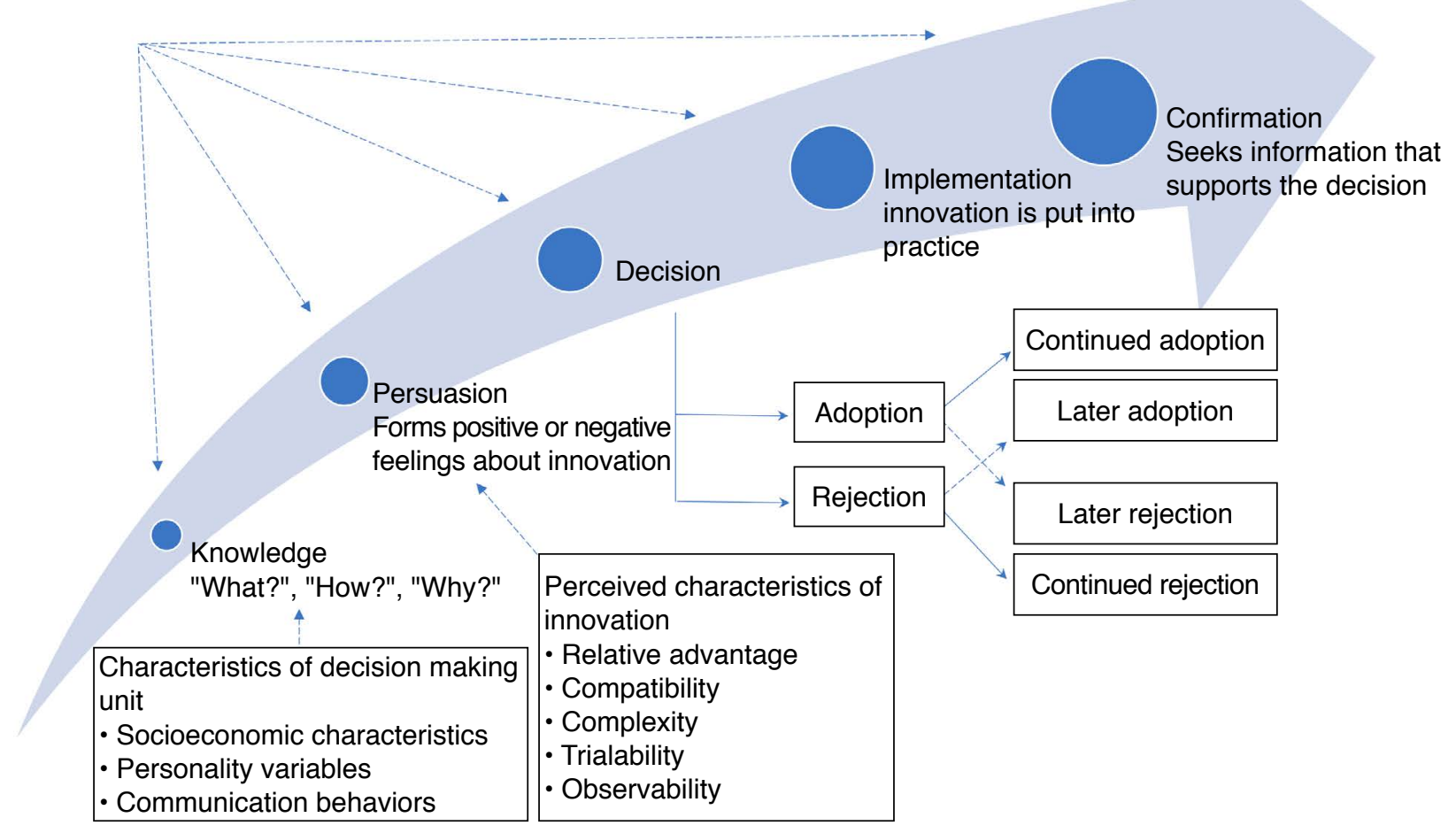

Fig. 3. A model of five stages in the innovation-decision process. Data from Diffusion of Innovations, 5th edition by Everett M. Rogers. Copyright (c) 2003 by The Free Press [12].

to adoption. The more that reinvention occurs, the more rapidly an innovation is adopted and becomes institutionalized.

In the final "confirmation stage," the individual looks for support for his or her decision. This decision can be reversed if the individual is "exposed to conflicting messages about the innovation," however, most individuals tend to minimize negative feedback and prioritize supportive messages that confirm their decision [12]. Later adoption or discontinuance happens during this stage, depending on the support for adoption of the innovation and the attitude of the individual. Discontinuance may also occur during this stage in which the individual rejects the innovation to adopt a better innovation that replaces it (replacement discontinuance), or the individual rejects the innovation because they are not satisfied with its performance or it does not meet the needs of the individual (disenchantment discontinuance) [12].

Not everyone goes through the five stages of adoption at a similar pace. Rogers [12] describes five adopter categories based on innovativeness, "the degree to which an individual or other unit of adoption is relatively earlier in adopting new ideas than other members of a system" (Fig. 4). For Rogers, innovativeness helps in understanding the main behavior in the innovation-decision process. He also notes that incomplete adoption and non-adoption do not form this adopter classification. Only adopters of successful innovations generate this curve over time. In this normal distribution, each category is defined using a standardized percentage of respondents.

"Innovators" are willing to experience new ideas and are the first to try an innovation. They are often willing to take risks and are prepared to cope with unprofitable and unsuccessful innovations, as well as a certain level of uncertainty about the innovation.

"Early Adopters" are more limited by the boundaries of the social system and are more likely to hold leadership roles and offer advice or information about the innovation. Although they may not be the very first to try an innovation, they are comfortable adopting new innovations early on. They are often called visionaries with the ability to discern the potential of different innovations.

Although the "Early Majority" still adopt innovations earlier than most, they are more pragmatic and deliberate in adopting an innovation and need to see evidence that it works before adopting it. They do not have the leadership role that early adopters have.

Similar to the Early Majority, the "Late Majority" includes onethird of all members of the social system who are more conservative 


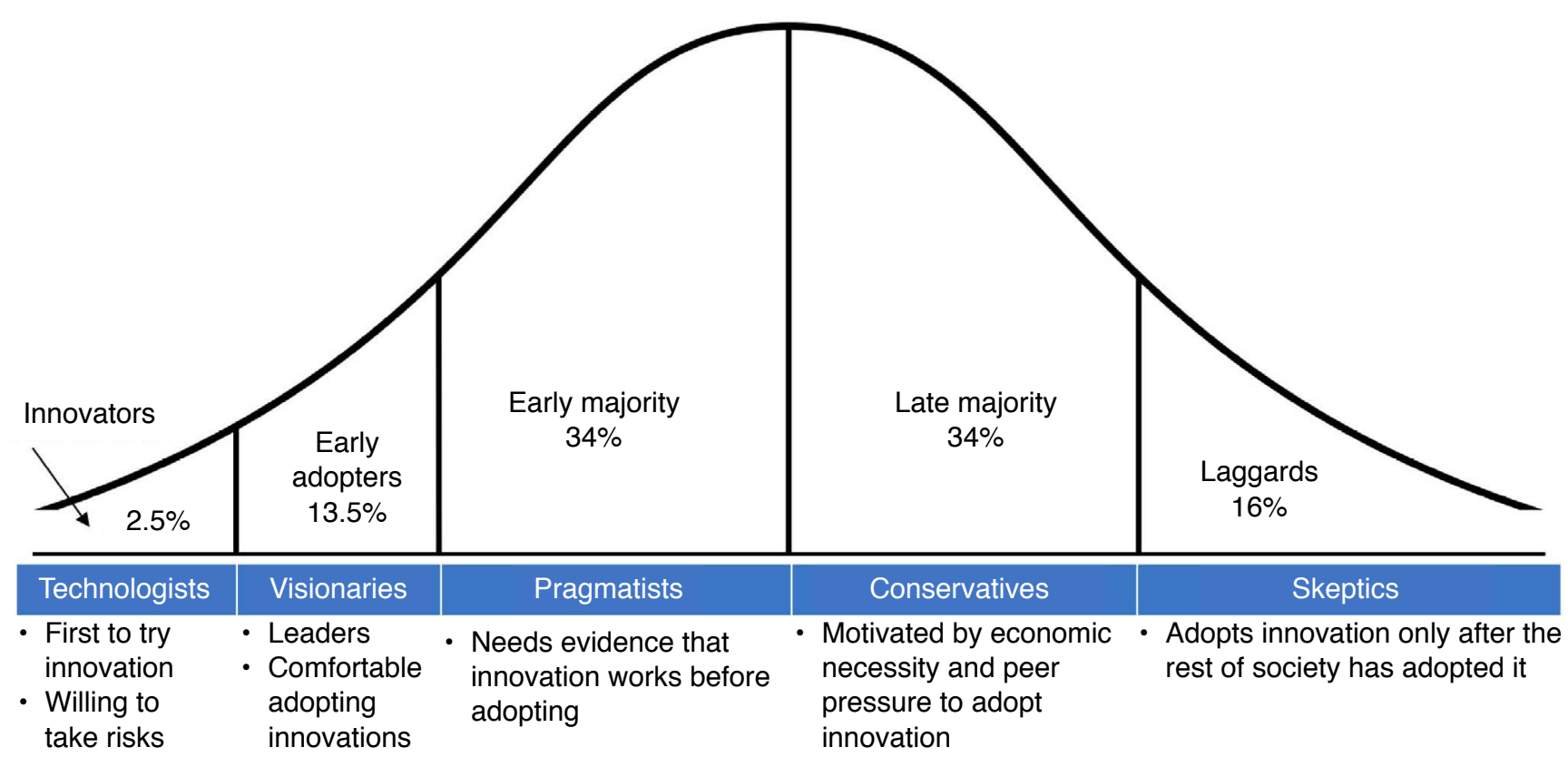

Fig. 4. Adopter categories. Data from Diffusion of Innovations, 5th edition by Everett M. Rogers. Copyright (c) 2003 by The Free Press [12].

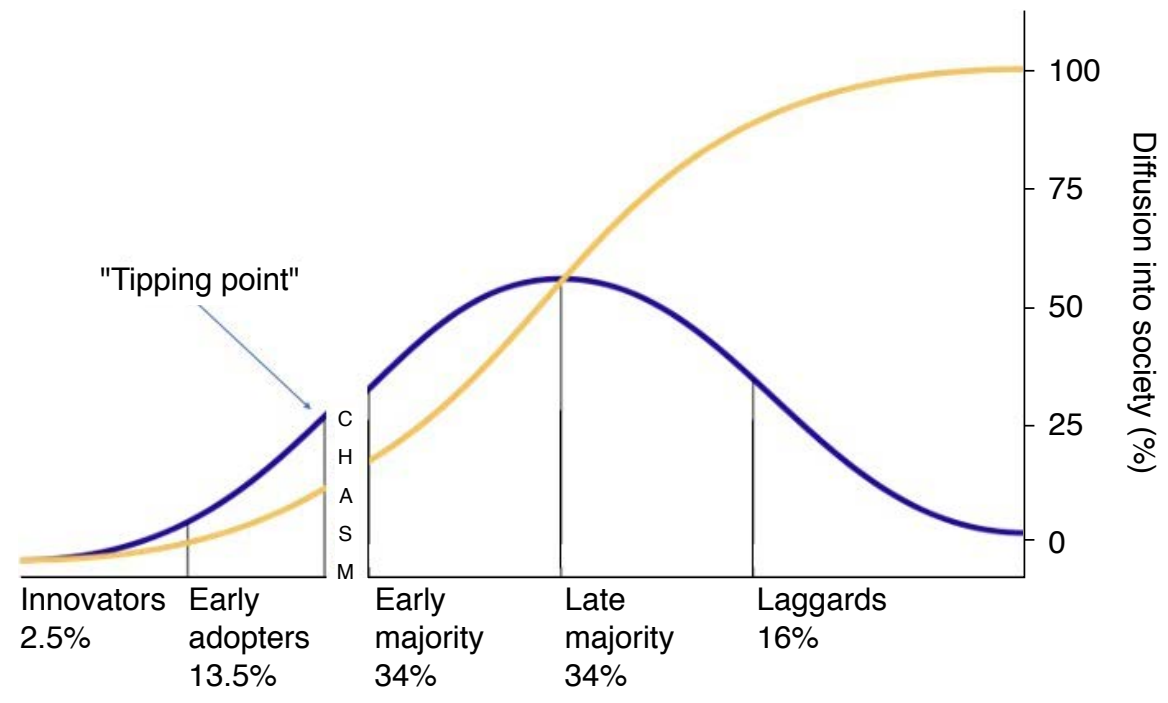

Fig. 5. Diffusion of innovation curve with adopter categories. Data from Diffusion of Innovations, 5th edition by Everett M. Rogers. Copyright (c) 2003 by The Free Press [12].

and wait until most of their peers adopt the innovation. They are often motivated by economic necessity and peer pressure to adopt an innovation.

Finally, the "Laggards" are skeptics and tend to adopt an innovation only after seeing that the innovation is successfully adopted by other members of the social system.

Innovators and Early Adopters are important determinants of the diffusion process of innovation [12] (Fig. 5). They can either accelerate the diffusion process through the 'tipping point' of the S-curve [15], or stall the diffusion process by converting the 'tipping point' into a 'chasm' [16]. The difference largely exists because, in contrast to Rogers' original theory, each category of adopters does not always act as an influencer and reference group for the category that follows it. Innovators and Early Adopters are creators and attracted by scarcity, i.e., they are drawn to innovations in large part because not everyone has it or is doing it yet [17]. The Early Majority, as well as Late Majority and even Laggards, are more drawn to social proof. They adopt an innovation largely because its value has been proven by others and they want what others have or have done [17]. Inherently, there is tension between Early Adopters and the Early Majority. Early Adopters have a vested interest in the Early Majority not adopting the innovation because it takes away from their scarcity needs. If the early adopters have too much control of the messaging of an innovation, they can stall the diffusion of the 
innovation because it benefits them to do so. Regardless of what the innovation is, this chasm and direct change in motivation of adoption occurs when approximately $16 \%$ of society has adopted the innovation (the so-called Maloney's 16\% Rule) [18]. In order to surpass the chasm, the messaging of the innovation needs to be changed. In marketing, once $16 \%$ of the population has enjoyed "being one of the first" to have an innovation, then the messaging has to change to "buy this innovation because so many people before you have already done so." The same change in messaging needs to occur with medical innovations. Although initial communications may focus more on the clinical validity of a rare innovation, in order for it to be more widely diffused, the messaging needs to shift to one focused on demonstrable efficacy and the societal good.

According to Rogers' paradigm, current adopters of RFA of thyroid nodules in the United States are likely Early Adopters. Although they did not create the innovation, they are comfortable adopting RFA because they believe in the potential of RFA as a treatment option for thyroid nodules. Moreover, many Early Adopters in the United States hold leadership positions in key organizations such as the American Thyroid Association (ATA), the American Association of Endocrine Surgeons (AAES), the Association of Head \& Neck Surgeons, and the Society of Interventional Radiologists. The messaging of these Early Adopters will be critical to the success of the adoption process of RFA in the United States.

\section{Social System}

The social system is the last element in the diffusion process. Rogers defined the social system as "a set of interrelated units engaged in joint problem solving to accomplish a common goal" [12]. Since diffusion of innovations takes place in the social system, it is influenced by the social structure of the social system. Health care is a very complex interplay of larger social systems that are not always receptive to change which can prove to be a tremendous hurdle for the adoption and implementation of medical innovation. There are several reasons for the perceived gap between evidencebased medicine and evidence-based practice. Medical innovation frequently involves emotional factors attached to the concept of health and illness as well as a political commitment to offer the latest advances in medicine [13]. Novel biomedical technologies have two, often contradictory aspects: the promise for better health and improved quality of life versus the associated higher cost of such services. These aspects may be especially difficult to reconcile within a context of scarce resources and a drive to reduce cost.

In healthcare, guidelines issued by various medical societies can help to navigate this dilemma. The Korean Society Guidelines for the
RFA of Thyroid Nodules [8], followed by the more recent European Thyroid Association guidelines [9], and the recommendations from the Asian Conference of Tumor Ablation Task Force [11], have established a firm societal infrastructure for the integration of RFA into treatment algorithms. The United States is poised to follow suit with several United States-based societies issuing guidelines incorporating discussions of RFA of thyroid nodules. However, guidelines are generally aimed at physicians. For an innovation to be adopted diffusely in healthcare, it must also be diffused among patients. If the benefit of the innovation is not clear or in high demand among patients, the diffusion of an innovation may stall. A good example of this stall in diffusion is remote access surgery for thyroidectomy. Although there was initial enthusiasm among surgeons for these approaches when they were introduced in the early 2010s, these approaches ultimately failed to appeal to a wider patient audience and has yet to reach wide-spread adoption in the United States.

An increasingly important component of the social system is social media platforms. Through social networking sites, blogs, forums, and similar platforms, it has become easier for the lay public to find health information and get the care they need. In fact, $99 \%$ of hospitals in the United States have an active Facebook page and the use of other social networking platforms like Twitter and Instagram in healthcare is also on the rise. One of the biggest benefits of social media in healthcare is information dissemination. It enables physicians, health institutions, and organizations to share discoveries, research, health tips, recommendations, and relevant news to the wider public. In addition, it serves as an important medium for patients to share information with each other. In the United States, social media platforms have played a crucial role in disseminating information about and increasing awareness of these ablation techniques. In particular, a Facebook group "Thyroid RFA and PEI Testimonials" run by Jennifer Holkem, has served both as a support group and valuable resource for patients seeking alternative non-surgical treatments for the management of their thyroid nodules. Ms. Holkem also hosts a YouTube channel featuring patient testimonials and interviews with physicians performing RFA. Her work has been a critical driver in accelerating the recognition of RFA in the United States.

\section{Future Directions}

Although a few cases of RFA of thyroid nodules had been performed in the United States previously, the technique did not establish a foundation in the United States until late 2019, when a few programs, largely clustered in the Northeast, started their RFA programs. The coronavirus disease (COVID) pandemic did slow the 
start of many programs, but nevertheless, additional programs have slowly launched across the country. The most common indications for RFA in the United States remain benign thyroid nodules, both non-functional and autonomously functioning. As yet unpublished data of several institutions suggests that overall outcomes are similar to international experience. Additionally, similar to the international experience, potential expansion of the indications for RFA are also being investigated. A couple of institutions are recruiting patients for clinical trials evaluating the safety and efficacy of RFA for treatment of indeterminate thyroid nodules that have been molecularly profiled benign (Columbia University), and low risk well-differentiated papillary thyroid carcinomas (The Mayo Clinic and Columbia University). Only a couple of institutions have used RFA to treat recurrent thyroid cancer (Columbia University and Oregon Health \& Sciences University).

As RFA, and other thermal ablation techniques, continue to expand in the United States, undoubtedly its role in the management of thyroid diseases, both benign and malignant, will need to be re-examined and considered. Several societies and organizations have begun this process including the ATA, AAES, American Head $\&$ Neck Society and the Society of Interventional Radiologists. The emerging experience from the United States will add valuable data and insight, and should be consolidated with the international experience, in formulating recommendations and guidelines for the safe implementation and adoption of thermal ablation techniques worldwide. Thermal ablation for thyroid disease is a unique confluence of multiple disciplines (endocrinology, surgery, and radiology) which provides a broad foundation for diffusion if we embrace and optimize international, multidisciplinary collaborations to educate, train, share experiences and advance the field.

\section{Conclusion}

By analyzing RFA of thyroid nodules using the framework provided by Rogers' DOI Theory, we are able to gain a greater understanding of its adoption process. RFA of thyroid nodules meets all of the attributes that comprise adoption of a successful innovation. Even though it has been over two decades since the concept was first introduced in Asia, the slow pace of adoption thus far, especially in the United States, is not necessarily unique or unexpected. Successful diffusion of innovations takes time and the early part of the curve in the United States has been blunted by the COVID pandemic. Additionally, many physicians in the United States are Early Adopters and will likely play a critical role in the progression of the adoption process. With careful messaging through the appropriate communication channels and promoting awareness among physicians and patients, these Early Adopters can potentially

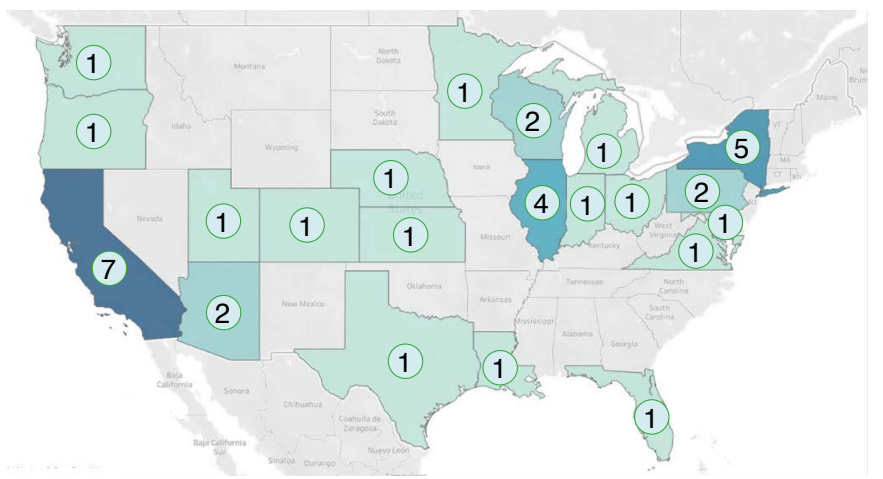

Fig. 6. Map of current and pending radiofrequency ablation programs in the United States (as of May 2021).

accelerate the adoption process through the tipping point, and promote wide-spread diffusion in a social system that appears primed to integrate RFA into existing practice. Concerted efforts of multidisciplinary organizations such as the North American Society of Interventional Thyroidology that work to educate and promote the adoption of RFA in a safe and effective manner will be important determinants of the diffusion process, both in the United States and abroad. Only time will tell how widely RFA for thyroid nodules is adopted. However, there is already some evidence that the curve is accelerating to the tipping point: currently, there are 13 established RFA programs in the United States (Supplementary Data 1). Over the next few months, 24 additional programs will begin offering RFA, greatly increasing access for patients who are interested in undergoing the procedure (Fig. 6).

ORCID: Jennifer H. Kuo: https://orcid.org/0000-0003-3745-9336; Catherine McManus: https://orcid.org/0000-0002-8241-2417; James A. Lee: https://orcid.org/0000-00029317-6077

\section{Author Contributions}

Conceptualization: Kuo JH, Lee JA. Data acquisition: Kuo JH. Data analysis or interpretation: Kuo JH, McManus C, Lee JA. Drafting of the manuscript: Kuo JH. Critical revision of the manuscript: McManus C, Lee JA. Approval of the final version of the manuscript: all authors.

\section{Conflict of Interest}

No potential conflict of interest relevant to this article was reported.

\section{Supplementary Material}

Supplementary Data 1. Current institutions offering radiofrequency ablation of thyroid nodules in the United States (as of June 30, 2021) (https://doi.org/10.14366/usg.21117). 


\section{References}

1. Haugen BR, Alexander EK, Bible KC, Doherty GM, Mandel SJ, Nikiforov YE, et al. 2015 American Thyroid Association management guidelines for adult patients with thyroid nodules and differentiated thyroid cancer: the American Thyroid Association Guidelines Task Force on Thyroid Nodules and Differentiated Thyroid Cancer. Thyroid 2016;26:1-133.

2. Gharib H, Papini E, Garber JR, Duick DS, Harrell RM, Hegedus L, et al. American Association of Clinical Endocrinologists, American College of Endocrinology, and Associazione Medici Endocrinologi medical guidelines for clinical practice for the diagnosis and management of thyroid nodules: 2016 update. Endocr Pract 2016;22:622-639.

3. Sosa JA, Bowman HM, Tielsch JM, Powe NR, Gordon TA, Udelsman $R$. The importance of surgeon experience for clinical and economic outcomes from thyroidectomy. Ann Surg 1998;228:320-330.

4. Brunaud L, Zarnegar R, Wada N, Ituarte P, Clark OH, Duh QY. Incision length for standard thyroidectomy and parathyroidectomy: when is it minimally invasive? Arch Surg 2003;138:1140-1143.

5. Graves $C E$, Suh I. The current status of remote access thyroidectomy in the United States. Surgery 2020;168:845-850.

6. Kuo JH, Lee JA. The Adoption of ultrasound-guided radiofrequency ablation of thyroid nodules in the United States. Ann Surg 2021;273:e10-e12.

7. Kim YS, Rhim H, Tae K, Park DW, Kim ST. Radiofrequency ablation of benign cold thyroid nodules: initial clinical experience. Thyroid 2006;16:361-367.

8. Kim JH, Baek JH, Lim HK, Ahn HS, Baek SM, Choi YJ, et al. 2017 Thyroid radiofrequency ablation guideline: Korean Society of Thyroid
Radiology. Korean J Radiol 2018;19:632-655.

9. Papini E, Monpeyssen H, Frasoldati A, Hegedus L. 2020 European Thyroid Association clinical practice guideline for the use of image-guided ablation in benign thyroid nodules. Eur Thyroid J 2020;9:172-185.

10. Lee M, Baek JH, Suh CH, Chung SR, Choi YJ, Lee JH, et al. Clinical practice guidelines for radiofrequency ablation of benign thyroid nodules: a systematic review. Ultrasonography 2021;40:256-264.

11. Ha EJ, Baek JH, Che Y, Chou YH, Fukunari N, Kim JH, et al. Radiofrequency ablation of benign thyroid nodules: recommendations from the Asian Conference on Tumor Ablation Task Force. Ultrasonography 2021;40:75-82.

12. Rogers EM. Diffusion of innovations. New York: Free Press, 2003.

13. Kelly CJ, Young AJ. Promoting innovation in healthcare. Future Healthc J 2017;4:121-125.

14. Park HS, Baek JH, Park AW, Chung SR, Choi YJ, Lee JH. Thyroid radiofrequency ablation: updates on innovative devices and techniques. Korean J Radiol 2017;18:615-623.

15. Gladwell M. The tipping point: how little things can make a big difference. Boston, MA: Back Bay Books, 2002.

16. Moore GA. Crossing the chasm: marketing and selling high-tech products to mainstream customers. New York: Harper Business, 2006.

17. Cialdini RB. Influence: the psychology of persuasion. New York: Harper Business, 2006.

18. Maloney C. The secret to accelerating diffusion of innovation: the $16 \%$ rule explained [Internet]. Jyväskylä: INNOVATE OR DIE, 2010 [cited 2021 May 30]. Available from: https://innovateordie.com.au/2010/05/10/thesecret-to-accelerating-diffusion-of-innovation-the-16-rule-explained/. 